E3S Web of Conferences 1, 39005 (2013)

DOI: $10.1051 / \mathrm{e} 3$ sconf $/ 20130139005$

(C) Owned by the authors, published by EDP Sciences, 2013

\title{
Survey on the presence of ${ }^{90} \mathrm{Sr}$ in milk samples by a validated ultra low level liquid scintillation counting (LSC) method
}

\author{
D. dell'Oro ${ }^{1}$, M. Iammarino ${ }^{1}$, N. Bortone ${ }^{1}$ and A. E. Chiaravalle ${ }^{1}$ \\ ${ }^{1}$ National Reference Center for the Detection of Radioactivity in Feed and Foodstuff, Istituto Zooprofilattico \\ Sperimentale della Puglia e della Basilicata, Italy, izsfgchimica@tiscali.it
}

\begin{abstract}
Sr}$ is one of the most biologically hazardous radionuclides produced in nuclear fission processes and decays emitting high-energy beta particles turning ${ }^{90} \mathrm{Y} .{ }^{90} \mathrm{Sr}$ is transferred from soil-plant to cow's milk and then to humans if it is introduced into the environment. Radiostrontium is chemically similar to calcium entering the human body through several food chains and depositing in bone and blood-forming tissue (bone marrow). Among main foodstuffs assumed in human diet, milk is considered of special interest for radiostrontium determination, especially in emergency situations, because the consumption of contaminated milk is the main source of internal radiation exposure, particularly for infants. In this work an analytical method for the determination of radiostrontium in milk was developed and validated in order to determine low activity levels by liquid scintillation counting (LSC) after achieving ${ }^{90} \mathrm{Y}$ secular equilibrium condition. The analytical procedure was applied both in surveillance and routine programmes to detect radiocontamination in cow's, goat and sheep milk samples.
\end{abstract}

Key words: ${ }^{90} \mathrm{Sr}$, milk, LSC, validation

\section{Introduction}

${ }^{90} \mathrm{Sr}$ is considered a radiotoxic isotope due to its long physical and biological half-life. It is produced in nuclear fission processes and decays to its radioactive daughter nuclide ${ }^{90} \mathrm{Y}$, emitting beta particles $\left(\mathrm{E}_{\max }=546 \mathrm{keV}\right) .{ }^{90} \mathrm{Y}$ is also a pure $\beta$-emitter with $\mathrm{E}_{\max }$ of $2284 \mathrm{keV}$ and is quikly in equilibrium with ${ }^{90} \mathrm{Sr}$ as a result of its short half life $(64.1 \mathrm{~h})$. Due to its similarity with calcium, ${ }^{90} \mathrm{Sr}$ is easily absorbed in humans through several food chains and it is accumulated in bones, where it emits its energetic $\beta$-particles with a half life of 28.8 years, posing a high risk to human health. Consequently, the monitoring of the levels of ${ }^{90} \mathrm{Sr}$ in environmental materials and foodstuffs is essential, particularly in milk that contains high amounts of calcium and is wide consumed especially by infants.

The EURATOM decree n. L 2218/89 defines the highest allowed levels of radiostrontium contamination on food products in case of nuclear accident. Limits of $125 \mathrm{~Bq} / 1$ and $75 \mathrm{~Bq} / 1$ have been established for ${ }^{90} \mathrm{Sr}$ in milk and milk products for babies, respectively.

Current national official methods [UNI, 1991 and 1994] are very laborious and time-consuming and it is necessary to develop an alternative method in contrast to traditional ones that use gas proportional counter. In the last years, different methods for the determination of ${ }^{90} \mathrm{Sr}$ in milk samples have been proposed [Vajda \& Kim, 2010], including radiometric and spectrometric techniques, but the necessary validation procedures are lacking. In this work an analytical method for the determination of radiostrontium in milk was optimized in order to obtain its determination at low activity levels by liquid scintillation counting (LSC).

The most difficult analytical step is the separation of ${ }^{90} \mathrm{Sr}$ from other alkaline earth elements, such as $\mathrm{Ca}$ and $\mathrm{Ba}$. $\mathrm{Y}$ is a transition metal belonging to the $3^{\text {rd }}$ subgroup of the periodic table, so the separation of $\mathrm{Y}$ is usually easier than $\mathrm{Sr}$, especially when big amounts of $\mathrm{Ca}$ and $\mathrm{Ba}$ are present in the sample. Y forms strong complexes with Bis-(2-ethylhexyl) phosphate (HDEHP) so it can be selectively extracted and then precipitated as oxalate until achievement of ${ }^{90} \mathrm{Sr} /{ }^{90} \mathrm{Y}$ secular equilibrium.

The method was validated following an in-house validation model and the most important performance parameters were evaluated in compliance with the international requirements for chemical methods [European Commission, 2002 and 2004]. The method has been applied successfully for the monitoring of various milk samples coming from Italy and collected 
from November 2011 to April 2012.

\section{Materials and Methods}

11 of milk was placed in a beaker and $1 \mathrm{ml}$ of $\mathrm{Sr}$ standard solution $(10.000 \mathrm{mg} / \mathrm{l})$ was added. The sample was mixed for 15 minutes by using a bar stirrer. $100 \mathrm{ml}$ of Dowex $50 \mathrm{WX}-8$ resin, previously conditioned, were added, then the $\mathrm{pH}$ value of solution was corrected to 8.5 by addition of $\mathrm{NaOH} 6 \mathrm{M}$. The mixture was mixed for 60 minutes by a bar stirrer and then the supernatant was discharged. 1.51 of warm water were added at least three times to wash the resin until the obtainment of a clear supernatant. The resin was placed into a chromatographic column and the $\mathrm{Sr}$ was eluted slowly with $200 \mathrm{ml}$ of $\mathrm{HNO}_{3} \quad 3 \mathrm{M}$ and $75 \mathrm{~mL}$ of water. The eluate was evaporated to dryness. The sample was maintained at room temperature for two weeks until achievement of ${ }^{90} \mathrm{Sr} /{ }^{90} \mathrm{Y}$ secular equilibrium.

The residue was dissolved with $200 \mathrm{ml}$ of $\mathrm{HCl} 0.1$ $\mathrm{M}$ and then $1 \mathrm{ml}$ of this solution was diluted to $50 \mathrm{~mL}$ with $\mathrm{HNO}_{3} \quad 0.1 \mathrm{M}$ in a volumetric flask for $\mathrm{Sr}$ determination by inductively coupled plasma mass spectrometry (ICP/MS).

$1 \mathrm{ml}$ of $\mathrm{Y}$ standard solution $(10.000 \mathrm{mg} / \mathrm{l})$ was added to the sample and the $\mathrm{pH}$ of solution was corrected to 1.0 by addition of $\mathrm{HCl} 0.1 \mathrm{M}$ or $\mathrm{NH}_{4} \mathrm{OH} 0.1 \mathrm{M}$. The solution was placed in a separatory funnel with $200 \mathrm{ml}$ of $5 \%$ HDEHP in toluene and mixed vigorously. The aqueous phase was discharged while the organic phase was purified two times with $200 \mathrm{ml}$ of $\mathrm{HCl} 0.1 \mathrm{M}$.

A liquid-liquid extraction of $\mathrm{Y}$ was achieved by using twice over $150 \mathrm{ml}$ of $\mathrm{HNO}_{3} 3 \mathrm{M} .50 \mathrm{ml}$ of $8 \%$ oxalic acid were added to the extract and the $\mathrm{pH}$ of solution was corrected to 2.5 by slow addition of a $15 \%$ $\mathrm{NH}_{4} \mathrm{OH}$ solution.

The mixture was heated in order to obtain the complete precipitation of Yttrium ossalate. After cooling the mixture was filtered under vacuum using Whatman 42 filters (Whatman, Springfield Mill, UK). The filtered residue was dissolved in 2-3 $\mathrm{ml}$ of Nitric acid and $5 \mathrm{ml}$ of $\mathrm{H}_{2} \mathrm{O}_{2}$ and the solution was evaporated to dryness. $8 \mathrm{ml}$ of $\mathrm{HCl} 0.1 \mathrm{M}$ were used to dissolve the residue $(50 \mu \mathrm{L}$ of this solution were diluted to $50 \mathrm{ml}$ by addition of $\mathrm{HNO}_{3}$ $0.1 \mathrm{M}$, this solution was used for $\mathrm{Y}$ determination by ICP-MS). $12 \mathrm{ml}$ of scintillation cocktail were added and the solution was used for to determination of ${ }^{90} \mathrm{Y}$ by ultra low level liquid scintillation counter (Quantulus Wallac 1220, PerkinElmer, Turku, Finland) with a 1000 minutes counting time. The energy of the particles is directly proportional to the photons emitted from the scintillation vial.

Lacking a specific normative to follow for the validation of radiochemical procedures, the analytical method described was validated by an in-house validation model.
Performance parameters of the method, such as trueness, precision, counting efficiency, selectivity, linearity and measurement uncertainty, were evaluated. Blank milk samples were fortified with known activities of ${ }^{90} \mathrm{Sr}(0.5$ and $1 \mathrm{~Bq} / \mathrm{l})$ and six replicates at each level were carried out for the determination of recovery percentage (trueness) and relative standard deviation (precision).

The absence of $\beta$-interferences was verified in the study of selectivity by analysing a blank milk sample fortified at $1 \mathrm{~Bq} / \mathrm{l}$ and effecting the counting after 10,61 and 147 hours.

The counting efficiency was evaluated by three different ${ }^{90} \mathrm{Sr}$ sources with an activity of $1 \mathrm{~Bq} / 1$ prepared from a reference solution $(1.08 \pm 0.02 \mathrm{~Bq} / \mathrm{g})$, after the ${ }^{90} \mathrm{Y}$ extraction according to the described method.

Decision Threshold and Detection Limit were determined by analysing six blank samples in compliance with ISO 11929:2010.

Instrumental linearity was verified by constructing a calibration curve with ${ }^{90} \mathrm{Sr}$ sources, with activities of a $1.5,95.48$ e $494.40 \mathrm{~Bq}$. The statistical analysis of the regression parameters were carried out by the UNICHIM software.

A reference material, IAEA-152 milk powder, was also tested for quality control purpose.

The measurement uncertainty was elaborated according to the bottom-up method by the opportune combination of all uncertainty factors that characterize the method (repeatability, $\mathrm{Sr}$ and $\mathrm{Y}$ chemical yields by ICP/MS, weights and volumes, counting error, reference material, and counting efficiency).

\section{Results and Discussion}

The LSC provides information about the energy distribution of the radiation with high counting efficiency $(89 \%)$ while background was kept at ultra low levels. No self absorption occurs as a consequence of the homogeneous distribution of the sample in the scintillation cocktail [Schönhofer, 1995].

As shown in figure 1, no interfering radionuclides were observed in spectra analyzed for the selectivity study. The shape of $\beta$-spectra has a characteristic maximum peak corresponding to the interesting radionuclide while the total counting decreases according to ${ }^{90} \mathrm{Y}$ decay. Method precision and trueness were demonstrated evaluating $\mathrm{CV} \%$ and recovery mean values equal to $13 \%$ and $102 \%$ respectively. In figure 2 is reported an overlay of LSC spectra of a blank milk sample and of a milk spiked at $0.5 \mathrm{~Bq} / 1$. The chemical yield of stable $\mathrm{Sr}$ and $\mathrm{Y}$, determined by ICP/MS, were $70 \%$ and $60 \%$ respectively. Decision Threshold and Detection Limit correspond to $0.003 \mathrm{~Bq} / 1$ and $0.006 \mathrm{~Bq} / 1(\alpha=\beta=0.05)$. Method accuracy was evaluated also analysing a reference material, a milk powder with a certified ${ }^{90} \mathrm{Sr}$ activity of $7.7 \pm 0.7 \mathrm{~Bq} / \mathrm{kg}$. 


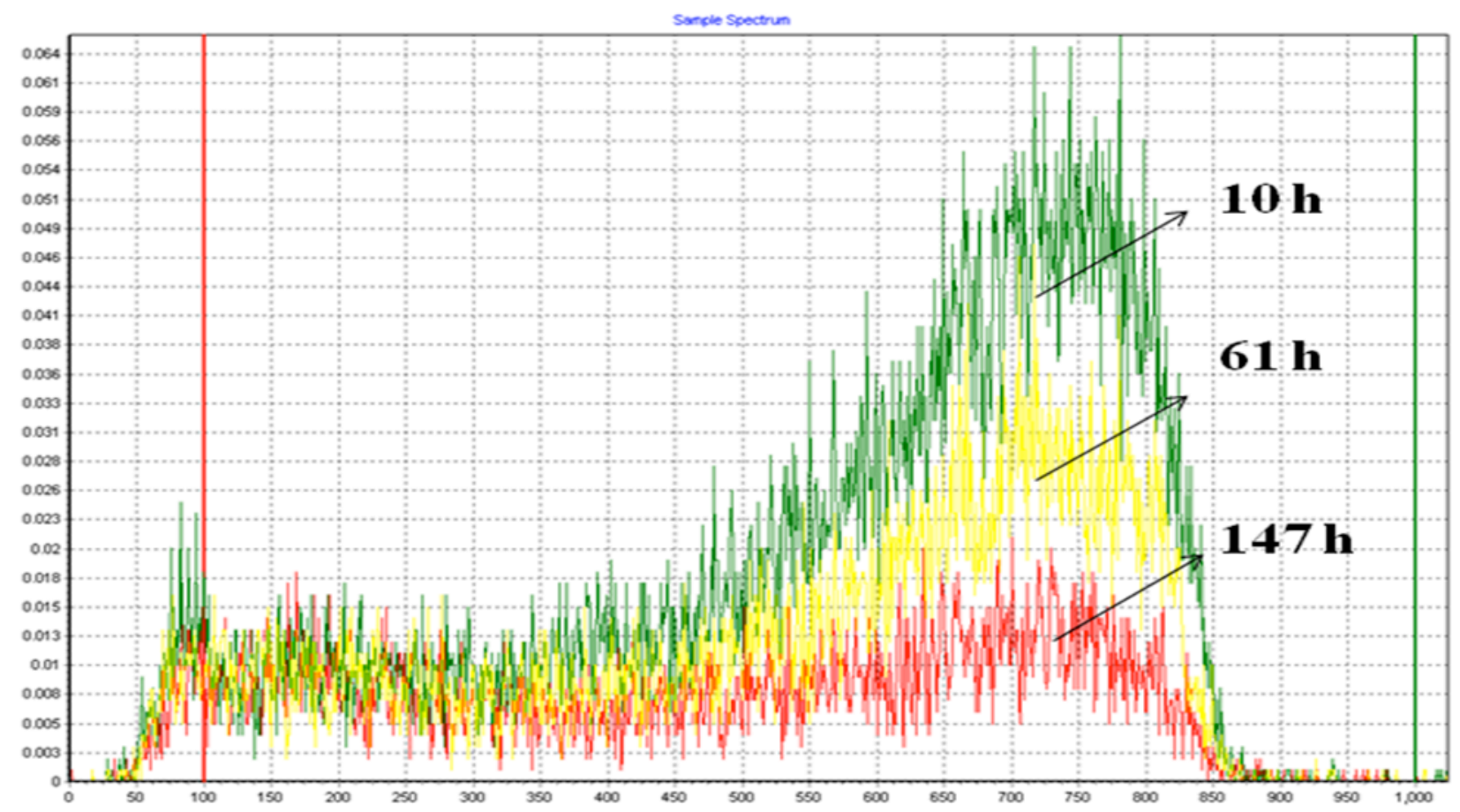

Fig. 1. Selectivity Study: spectra of milk sample spiked at $1 \mathrm{~Bq} / 1$ and counted after $10 \mathrm{~h}, 61 \mathrm{~h}$ and147 h.

The reference material was produced from cow's milk obtained from animals grazed on land contaminated by radioactive fallout resulting from the Chernobyl incident (1986). The sample was reconstituted with deionised water and analysed, obtaining a ${ }^{90} \mathrm{Sr}$ experimental value of $7.16 \pm 1.24 \mathrm{~Bq} / \mathrm{kg}(\mathrm{p}=0.95, \mathrm{k}=2)$ that match with reference data.

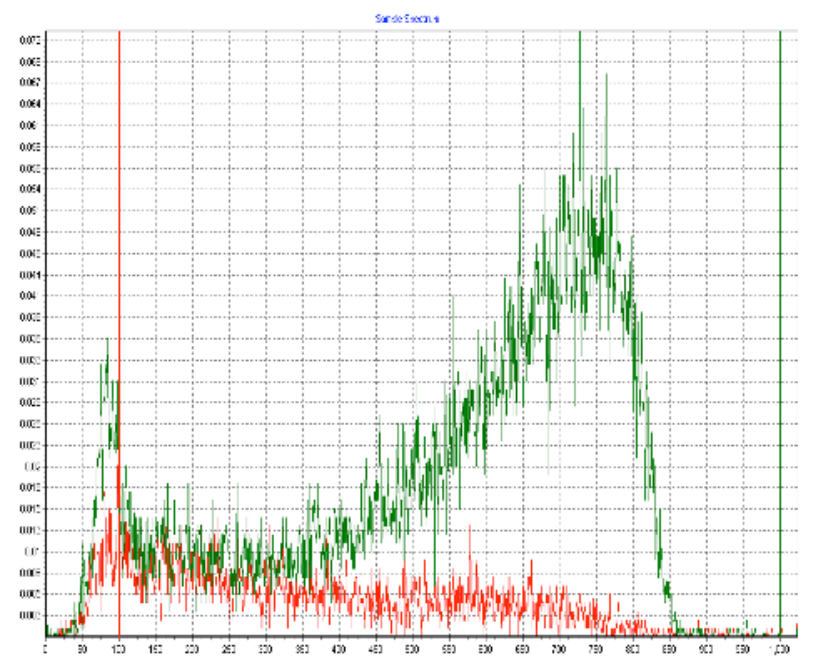

Fig. 2. LSC spectra of a blank milk sample (red) and of a milk spiked at $0.5 \mathrm{~Bq} / 1$ (green).

In order to assess the reliability of the analytical procedure and the potential of the proposed approach for routine analyses of ${ }^{90} \mathrm{Sr}, 47$ samples of cow's, goat and sheep milk were collected from several Italian farms and analysed. The results are reported in table 1.
The radioactive concentrations of ${ }^{90} \mathrm{Sr}$ detected, correlated to the isotope activity accumulated in soil, are very lower than legal limits. The amount of radioactive elements in food of animal origin depends also on their metabolism in the animal organism and particularly $\mathrm{Sr}$ is closely connected with Ca [Crout et al, 1998].

Table 1. Content of ${ }^{90} \mathrm{Sr}$ in milk samples

\begin{tabular}{|c|c|c|c|}
\hline Milk & $\begin{array}{c}\text { N. of } \\
\text { samples }\end{array}$ & $\begin{array}{c}{ }^{90} \text { Sr mean } \\
\text { activity (Bq/l) }\end{array}$ & $\begin{array}{c}{ }^{90} \text { Sr range } \\
\text { (Bq/l) }\end{array}$ \\
\hline Goat & 26 & 0.13 & $0.01-0.22$ \\
\hline Sheep & 14 & 0.15 & $0.03-0.21$ \\
\hline Cow's & 7 & 0.06 & $0.02-0.09$ \\
\hline
\end{tabular}

Kruk \& Solecki (2011) demonstrated that in cows fed with ${ }^{90} \mathrm{Sr}$ contaminated fodder about $0.08 \%$ of radioisotope gets in milk. For goat milk it may be even more than ten times higher since larger proportion between calcium amount adsorbed with food and that discharged with milk.

This was confirmed by our preliminary study since the highest ${ }^{90} \mathrm{Sr}$ activities were detected in goat and sheep milk samples (table 1).

Moreover, ANOVA test one way demonstrated that cow's milk samples shown a statistically significant difference from sheep and goat one.

\section{Conclusions}

The method developed and validated for the 
determination of ${ }^{90} \mathrm{Sr}$ in milk samples by ${ }^{90} \mathrm{Y}$ counting is efficient and reliable for confirmatory analysis. Sample preparation is simpler than official methods and extract selectively the desired radionuclide, without interferences. Experimental results are satisfactory and the analytical procedure is able to carry out both surveillance and routine programs at very low level radiocontamination.

The investigation performed on 47 milk samples of different origin demonstrated a ${ }^{90} \mathrm{Sr}$ contamination very lower than legal limits and a significant difference between cow's milk in respect to goat and sheep milk.

\section{Acknowledgements}

This study was carried out with the technical assistance of D. Annicchiarico.

\section{References}

Crout NMJ, Beresford NA, Howard BJ, Mayes RW, Hansen HS. A model of radiostrontium transfer in dairy goats based on calcium metabolism. J Dairy
Sci 1998; 81(1): 92-99.

European Commission Regulation (EC) N. 882/2004, 29 April 2004, Journal of the European Union, L165, $1-41$.

European Commission Decision 2002/657/EC, Journal of the European Union, L221, 8-36.

Kruk M, Solecki J. Studies of ${ }^{90} \mathrm{Sr}$ in milk and commercial dairy products. J Radioanal Nucl Chem 2011; 290:325-332.

Schönhofer F. Liquid scintillation spectrometry in environmental measuraments. The Science of the Total Environment 1995, 173/174 29-40.

UNI 9882:1991- Determinazione dei principali radionuclidi nel latte.

UNI 10374:1994 - Metodo rapido di determinazione di ${ }^{90} \mathrm{Sr}$ e di ${ }^{89} \mathrm{Sr}$ nel latte e in matrici similari.

UNICHIM. 2006. "Software applicativo per l'elaborazione dei risultati analitici".

Vajda N, Kim CK. Determination of radiostrontium isotopes: A review of analytical methodology. Applied Radiation and Isotopes 2010; 68:2306-2326. 